\title{
Factors related to depression and anxiety in adults with bronchiectasis
}

This article was published in the following Dove Press journal:

Neuropsychiatric Disease and Treatment

23 November 2016

Number of times this article has been viewed

\author{
Elif Yelda Özgün \\ Niksarlioglu' \\ Gülcihan Özkan² \\ Gülșah Günlüoğlu' \\ Mehmet Atilla Uysal' \\ Sule Gül' \\ Lütfiye Kilic' \\ Ayse Yeter ${ }^{\prime}$ \\ Güngör Çamsarı' \\ 'Department of Chest Disease, \\ Yedikule Chest Disease and \\ Thoracic Surgery Training and \\ Research Hospital, ${ }^{2}$ Department \\ of Chest Disease, Yeniyüzyıl \\ University Gaziosmanpasa Hospital, \\ Istanbul, Turkey
}

Introduction and background: Patients with chronic lung diseases frequently have depressive and anxiety symptoms, but there are very few studies looking at this in patients with bronchiectasis.

Aim: This study aimed to investigate depression and anxiety and related factors among patients with non-cystic fibrosis bronchiectasis.

Patients and methods: This was a prospective study of 133 patients with bronchiectasis. Patients with confirmed diagnosis of bronchiectasis with high-resolution computed tomography were enrolled in the study. Patients that were clinically stable in the previous 4 weeks were evaluated with the Hospital Depression and Anxiety scale. Symptoms, pulmonary function tests, and medical treatments were recorded.

Results: The mean age of patients was $49.5 \pm 14.5$ years (range, 18-77 years), and $81(60.9 \%)$ patients were females. Twenty-eight $(21.1 \%)$ patients had depression, and $53(39.8 \%)$ had anxiety. Depression score was related to family situation (living with a partner), previous depression history and admission to an emergency department within the last year. Anxiety score was related to female gender, the family situation (living with a partner), previous depression history, and admission to an emergency department within the last year $(P<0.05)$. Depression was positively correlated with hemoptysis, admission to an emergency department within the last year and living with a partner. Anxiety was positively correlated with education level, previous depression history, admission to an emergency department within the last year, and living with a partner.

Conclusion: Patients with non-cystic fibrosis bronchiectasis are at increased risk for depression and anxiety. Untreated and undetected depressive/anxiety symptoms may increase physical disability, morbidity, and health care utilization. It is important for clinicians to be aware of the presence of depression and anxiety in bronchiectasis.

Keywords: anxiety, bronchiectasis, depression, risk factor

\section{Introduction}

Bronchiectasis is defined as irreversible, abnormal dilatation of one or more bronchi with chronic airway inflammation and results in a chronic cough, sputum production, recurrent chest infection, and airflow obstruction. ${ }^{1,2}$ According to US data, the estimated prevalence of bronchiectasis is 53 cases per 100,000 adults. ${ }^{3}$ Seitz et al reported that prevalence of bronchiectasis was 1,106 cases per 100,000 people. ${ }^{4}$ The prevalence increases with age and is higher in females. As it is a chronic disease, bronchiectasis may lead to a decrease in exercise capacity and cause difficulty in performing daily living activities.

Ryu et al reported that depression and anxiety are more prevalent in subjects with chronic airway diseases, and this is associated with low quality of life and impaired
Correspondence: Elif Yelda Özgün Niksarlioglu

Department of Chest Disease, Yedikule Chest Disease and Thoracic Surgery

Training and Research Hospital, Belgrad kapi yolu street no I, Zeytinburnu,

Istanbul, Turkey

Tel +902124090200

Fax +902125472233

Email eyelda2003@yahoo.com
Neuropsychiatric Disease and Treatment 2016:12 3005-3010

3005

Dovepress f in 0

http: //dx.doi.org/10.2147/NDTSI21147

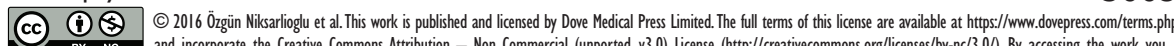
cc. hereby accept the Terms. Non-commercial uses of the work are permitted without any further permission from Dove Medical Press Limited, provided the work is properly attributed. For permission for commercial use of this work, please see paragraphs 4.2 and 5 of our Terms (https://www.dovepress.com/terms.php). 
adherence to therapy. ${ }^{5}$ Similarly, although psychiatric disorders such as anxiety and depression are related to worsened respiratory symptoms, increased health expenditure, and noncompliance with therapy in the patients with chronic pulmonary diseases, it may frequently be overlooked in daily practice. ${ }^{6,7}$ There are a limited number of studies on the prevalence of depression and anxiety in either pediatric or adult cases with bronchiectasis, which is a significant chronic pulmonary problem. ${ }^{8-10}$

In the present prospective study, we aimed to investigate the presence of depression and anxiety in outpatients with non-cystic fibrosis bronchiectasis using the Hospital Anxiety Depression scale. In addition, we evaluated the relationship between sociodemographic, clinical factors and depression and anxiety in adult patients with bronchiectasis.

\section{Patients and methods}

A total of 133 patients with stable bronchiectasis who were diagnosed using high-resolution computed tomography (HRCT) enrolled to the study. Cases with cystic fibrosis, malignancy, interstitial pulmonary disease on HRCT and acute exacerbation of bronchiectasis were excluded. An acute exacerbation was defined as having at least three of the following criteria: worsened dyspnea and coughing, an increase in the amount and purulence of sputum, hemoptysis, fever $\left(\geq 38^{\circ} \mathrm{C}\right)$, worsening in clinical examination, and the presence of new signs on a chest X-ray. Demographic data, body mass index, marital status, education, occupation, smoking status, and comorbidity status were recorded for all patients. In addition, clinical characteristics of the patients, medications, the use of nebulizers (nebulizer is used for inhaled betamimetic and/or inhaled steroid drugs) and long-term oxygen therapy (LTOT; long-term oxygen therapy is extended use of oxygen; oxygen therapy is delivered as a gas from an oxygen source like concentrator), number of emergency and hospital admissions and intensive care stays within the last year, and pulmonary function tests were recorded.

After clinical and radiological examination, Hospital Anxiety Depression Scale (HADS) was performed on the stable patients. HADS was developed in 1983 by Zigmond and Snaith, and validity and reliability were performed. ${ }^{11}$ HADS questionnaire is a test consisting of 14 questions, of which seven are used to assess depression and the remaining seven are used to assess anxiety. The answers were evaluated in the form of four-point Likert-type scale. The scale was scored between 0 (best) and 3 (worst). Total score ranges between 0 and 21 points. While the cutoff value is 7 for depression, it is 10 for anxiety in the Turkish version. Validation of the Turkish version of the test was done in 1997. ${ }^{12}$

The study protocol was approved by the Local Ethics and Clinical Research Committee of the Yedikule Chest Diseases and Thoracic Surgery Training and Research Hospital. All participants gave written informed consent.

\section{Statistical analyses}

Statistical analyses were carried out using SPSS Statistics for Windows, version 20.0 (IBM Corporation, Armonk, NY, USA). Descriptive data were presented as mean \pm standard deviation, and median (range), when there is not a normal distribution. The univariate analyses to identify variables associated with patient outcome according to the HADS scores (anxiety and depression) was investigated using chisquare and Fisher exact tests. For the multivariate analysis, the possible factors identified with univariate analyses were further entered into the logistic regression analysis to determine independent predictor of patient outcome. Hosmer-Lemeshow goodness of fit statistics were used to assess model fit. A 5\% type-I error level $(P<0.05)$ was used to interpret statistical significance.

\section{Results}

A total of 133 patients with bronchiectasis were enrolled in this study. The mean age of patients was $49.5 \pm 14.5$ years (range, 18-77 years), and 81 (60.9\%) of the patients were females. The mean diagnosed time of the study group was $6.8 \pm 4$ years (range, 1 month-30 years). The baseline characteristics of the 133 patients are shown in Table 1.

The clinical symptoms of the patients included in this study are summarized in Table 1. No statistically significant difference was found between the groups with high and low depression and anxiety scores regarding symptoms (cough, sputum, dyspnea, and hemoptysis) $(P>0.05)$. Concerning medical therapies, 111 (83.5\%) were receiving bronchodilators, 17 (12.8\%) were using nebulizers, and 14 (10.5\%) were on LTOT. When comparing medical therapy for bronchiectasis and HAD scale scores, no statistically significant difference was found between the groups $(P>0.05)$. Furthermore, no relationship was found between the use of a nebulizer, LTOT and depression and anxiety $(P>0.05)$.

The mean HADS score was $10.9 \pm 8.3$; the mean depression score was $4.8 \pm 4.3$, and the mean anxiety score was 6.1 \pm 4.7 . The cutoff point for depression and anxiety was taken as 7 and 10, respectively, and therefore, 28 (21.1\%) patients had depression, and 53 (39.8\%) had anxiety. Depression score was related to the family situation (living 
Table I Demographic characteristics of patients

\begin{tabular}{|c|c|}
\hline Variables & Results $(n=133) *$ \\
\hline Age (years) & $49.5 \pm 14.5$ \\
\hline Female & $81(60.9)$ \\
\hline Male & $52(39.1)$ \\
\hline \multicolumn{2}{|l|}{ Smoking habit } \\
\hline Nonsmoker & $76(65.3)$ \\
\hline Active smoker & $45(33.8)$ \\
\hline Ex-smoker & $12(9)$ \\
\hline \multicolumn{2}{|l|}{ Family situation } \\
\hline With partner/other family member & $108(81.2)$ \\
\hline Live alone & $21(18.8)$ \\
\hline \multicolumn{2}{|l|}{ Level of education } \\
\hline$<8$ years & $84(63.1)$ \\
\hline$\geq 8$ years & $49(36.9)$ \\
\hline Employment & $68(5 \mathrm{I} .1)$ \\
\hline Unemployed & $65(48.9)$ \\
\hline Comorbidity** & $41(34.6)$ \\
\hline No comorbity & $87(65.4)$ \\
\hline History of depression & $42(31.6)$ \\
\hline History of anxiety & $13(9.8)$ \\
\hline $\mathrm{FEV}_{1}, \%$ & $62.2(23.8)$ \\
\hline FVC,\% & $68.2(2 \mid .2)$ \\
\hline $\mathrm{FEV} / \mathrm{FVC}$ & $71.7(13.8)$ \\
\hline \multicolumn{2}{|l|}{ Symptoms } \\
\hline Cough & $109(82)$ \\
\hline Dyspnea & $102(76.7)$ \\
\hline Sputum & 77 (57.9) \\
\hline Hemoptysis & $40(30.1)$ \\
\hline Admission to emergency department & $65(48.9)$ \\
\hline \multicolumn{2}{|l|}{ within the last year } \\
\hline Hospitalization & $20(15)$ \\
\hline
\end{tabular}

Notes: *Data are shown as: $\mathrm{n}(\%)$ or $\mathrm{X} \pm \mathrm{SD}$. **Hypertension, diabetes mellitus, coronary arterial disease, or gastroesophageal reflux.

Abbreviations: SD, standard deviation; $\mathrm{FEV}_{1}$, forced expiratory volume I second; FVC, forced vital capacity.

without a partner), previous depression history and admission to the emergency department within the last year. Anxiety score was related to female gender, employment, family situation (living without a partner), previous depression history, and admission to the emergency department within the last year (Table 2).

The first stepwise multivariate model for depression was performed which included the variables: age, gender, family situation, comorbidity, hospitalization, admission to an emergency department within the last year, and history of depression and anxiety. This model showed that living with a partner (odds ratio [OR] $0.17695 \%, 95 \%$ confidence interval [CI]: $0.459-0.675, P=0.011)$ and admission to the emergency department in last year (OR 4.236, 95\% CI: 1.277-14.0522, $P=0.018$ ) were independently related to depression. When the symptoms were added to the model, only hemoptysis (OR $0.255,95 \%$ CI: $0.687-0.948, P=0.041$ ) was a significant predictor of high scores of depression
(Table 3). However, pulmonary function tests did not affect the risk of depression in adults with bronchiectasis.

The multivariate model was performed including age, gender, employment, family situation, comorbidity, admission to the emergency department within the last year, hospitalization within the last year, and history of anxiety and depression for anxiety. This analysis identified four variables related to increased risk for clinically relevant anxiety: living with a partner (OR 0.075, 95\% CI: $0.015-0.358, P=0.001)$, education level ( $<8$ years) (OR 7.613, 95\% CI: 1.514-3.2570, $P=0.014$ ), admission to emergency department within the last year (OR 3.177, 95\% CI: $1.041-9.695, P=0.04)$, and history of depression (OR 7.170, 95\% CI: 2.317-22.1847, $P=0.001$ ) (Table 4). When symptoms and/or pulmonary function tests were added to the analysis, none of the symptoms were independent risk factors for anxiety, with living with a partner, education level ( $<8$ years), admission to an emergency department within the last year and history of depression remaining significant.

\section{Discussion}

In the present study, we found that depression and anxiety ratios were high in adults with bronchiectasis, similar to that found in previous studies ${ }^{8,9}$ Clinically significant depression was associated with living with a partner, admission to the emergency department within the last year and hemoptysis. These parameters were independent risk factors for depression with bronchiectasis. Also, anxiety was significantly associated with living with a partner, education level ( $<8$ years), previous depression history and admission to the emergency department within the last year.

Today, depression and anxiety are an important health problem in both developed and developing countries. According to data from the World Health Organization, the prevalence of depression ranges from 3\% to $16.9 \% \cdot{ }^{13}$ Despite the availability of studies on the prevalence of depression and anxiety and the related risk factors in chronic respiratory diseases, particularly in COPD, there is a limited number of studies published on the prevalence of depression and anxiety in adult patients with bronchiectasis. ${ }^{5,14,15}$ A limited number of previous studies in the literature reported a higher prevalence of depression and anxiety in bronchiectasis cases in comparison to general population. ${ }^{8,9}$ Olveria et al reported depression symptoms in $12.68 \%$ and anxiety symptoms in $18 \%$ of bronchiectasis cases evaluated by the HADS. ${ }^{9}$

Girón Moreno et al in their article published in 2013, reported depression in 34\% and trait and state anxiety in 55\% of non-cystic fibrosis bronchiectasis cases. They indicated 
Table 2 Factors associated with depression and anxiety in patients with bronchiectasis

\begin{tabular}{|c|c|c|c|c|c|c|}
\hline & \multicolumn{3}{|l|}{ HAD-D } & \multicolumn{3}{|l|}{ HAD-A } \\
\hline & $<7$ & $\geq 7$ & $P$-values & $<10$ & $\geq 10$ & $P$-values \\
\hline Number & 105 (78.9) & $28(2 I . I)$ & & $80(60.2)$ & $53(39.8)$ & \\
\hline Age, years & $49.6 \pm 14.5$ & $48.7 \pm \mid 4.5$ & $>0.05$ & $50.8 \pm \mid 4.1$ & $47.9 \pm 14.9$ & $>0.05$ \\
\hline Female & 61 (45.8) & $20(15)$ & $>0.05$ & $4 \mathrm{I}(30.8)$ & $40(30.1)$ & 0.005 \\
\hline Male & $44(33.1)$ & $8(6)$ & & $39(29.3)$ & $13(9.8)$ & \\
\hline \multicolumn{7}{|l|}{ Smoking } \\
\hline Never smoker & $60(45.5)$ & $17(12.9)$ & $>0.05$ & $44(33.3)$ & $33(25)$ & $>0.05$ \\
\hline Ever smoker & $44(33.3)$ & II (8.3) & & $35(26.5)$ & $20(15.2)$ & \\
\hline Employment & $48(37.5)$ & $17(13.3)$ & $>0.05$ & $33(25.8)$ & $32(25)$ & 0.028 \\
\hline Nonemployment & $52(40.6)$ & II (8.6) & & $44(34.4)$ & $19(14.8)$ & \\
\hline \multicolumn{7}{|l|}{ Family situation } \\
\hline Live alone & $23(17.3)$ & $12(9)$ & $<0.05$ & $10(7.5)$ & $15(11.3)$ & 0.022 \\
\hline With partner/other family member & $92(69.2)$ & $16(12)$ & & $70(52.6)$ & $38(28.6)$ & \\
\hline No history of depression & $76(57.1)$ & $15(11.3)$ & 0.05 & $65(48.9)$ & $26(19.5)$ & $<0.05$ \\
\hline History of depression & $29(21.8)$ & $13(9.8)$ & & $15(1 \mathrm{I} .3)$ & $27(20.3)$ & \\
\hline \multicolumn{7}{|l|}{ PFTs } \\
\hline $\mathrm{FEV}_{1}, \%$ predicted & $63.9(24.5)$ & $56.1(20.6)$ & $>0.05$ & $64.1(23.8)$ & $59.5(23.8)$ & $>0.05$ \\
\hline FVC, \% predicted & $68.9(21.1)$ & $65.7(21.7)$ & $>0.05$ & $69.1(21.1)$ & $67.1(21.4)$ & $>0.05$ \\
\hline $\mathrm{FEV} / \mathrm{FVC}$ & $72.3(14.4)$ & $69.8(11.3)$ & $>0.05$ & $72.1(13.2)$ & $71.2(14.6)$ & $>0.05$ \\
\hline No admission to an emergency department & $59(44.4)$ & $9(6.8)$ & 0.023 & $47(35.3)$ & $21(15.8)$ & 0.031 \\
\hline Admission to an emergency department & $46(34.6)$ & $19(14.3)$ & & $33(24.8)$ & $32(24.1)$ & \\
\hline No hospitalization & 89 (66.9) & $24(18)$ & $>0.05$ & $69(51.9)$ & $44(33.1)$ & $>0.05$ \\
\hline Hospitalization & $16(12)$ & $4(3)$ & & II (8.3) & $9(6.8)$ & \\
\hline
\end{tabular}

Notes: Data presented as mean \pm SD or $\mathrm{n}(\%)$. Cutoff point for depression is 7 points and 10 points for anxiety. Statistically significant parameters are shown as a bold value.

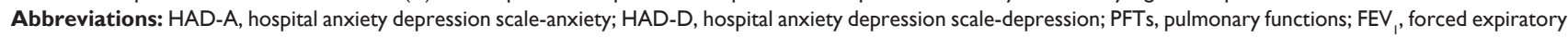
volume I second; FVC, forced vital capacity.

that depressive symptoms were more prevalent in females and that anxiety was associated with the daily amount of sputum and presence of bacterial colonization in the sputum. ${ }^{8}$ In the present patient population, female gender was associated with anxiety; however, no relationship was found between the amount of sputum and depression and anxiety. A study on patients with COPD, which is also a chronic airway disease, assessed depression, anxiety, pain, and quality of life and reported more severe anxiety and depression and poorer quality of life in the female patient group. ${ }^{16}$ Most of

Table 3 Predictive factors for depression in patients with bronchiectasis

\begin{tabular}{lll}
\hline Factors & OR $\mathbf{( 9 5 \% ~ C I )}$ & P-values \\
\hline Age & I.0I0 (0.964-I.058) & 0.654 \\
Male gender & $1.172(0.349-3.927)$ & 0.797 \\
Live with a partner & $0.176(0.459-0.675)$ & $\mathbf{0 . 0 I ~ I ~}$ \\
Comorbidity & $0.692(0.201-2.382)$ & 0.560 \\
Depression history & $2.521(0.842-7.549)$ & 0.098 \\
Panic disorder history & $2.372(0.737-7.637)$ & 0.148 \\
Admission to an & $4.236(\mathrm{I} .277-14.0522)$ & $\mathbf{0 . 0 1 8}$ \\
emergency department & & \\
Panic disorder history & $1.932(0.433-8.627)$ & 0.148 \\
Hospitalization & $0.426(0.768-2.309)$ & 0.388 \\
Hemoptysis & $0.255(0.687-0.948)$ & $\mathbf{0 . 0 4 I}$ \\
\hline
\end{tabular}

Note: Statistically significant parameters are shown as a bold value. Abbreviations: OR, odds ratio; $\mathrm{Cl}$, confidence interval. the earlier studies indicate female gender as an independent risk factor for depression and anxiety.

In the present study, investigating the relationship between respiratory symptoms and depression and anxiety in bronchiectasis cases, we found that only hemoptysis was an independent risk factor for depression, while anxiety was not associated with any of the symptoms. Goldbeck et al found that hemoptysis and recurrent pneumothorax were associated with anxiety, whereas impaired pulmonary function tests and being a lung transplant candidate were

Table 4 Logistic regression analysis for elevated symptoms for anxiety in patients with bronchiectasis

\begin{tabular}{lll}
\hline Factors & OR (95\% Cl) & P-values \\
\hline Age & $1.000(0.950-1.047)$ & 0.988 \\
Male gender & $0.421(0.140-1.125)$ & 0.124 \\
Education, $<8$ years & $7.613(1.514-3.2570)$ & $\mathbf{0 . 0 1 4}$ \\
Live with a partner & $0.075(0.015-0.358)$ & $\mathbf{0 . 0 0 I}$ \\
Depression history & $7.170(2.317-22.1847)$ & $\mathbf{0 . 0 0 I}$ \\
Panic disorder history & $2.625(0.415-16.57 \mid 3)$ & 0.305 \\
Comorbidity & $0.619(0.184-2.077)$ & 0.438 \\
Admission to & $3.177(1.041-9.695)$ & $\mathbf{0 . 0 4 2}$ \\
emergency department & & \\
Hospitalization & $0.637(0.113-3.59 I)$ & 0.610 \\
\hline
\end{tabular}

Note: Statistically significant parameters are shown as a bold value. Abbreviations: OR, odds ratio; $\mathrm{Cl}$, confidence interval. 
associated with depression in 670 patients with cystic fibrosis aged between 12 and 64 years. ${ }^{17}$ Hemoptysis is a common and distressing symptom in bronchiectasis cases, particularly during exacerbations. For this reason, recurrent hemoptysis, in particular, may promote depressive mood despite the fact that we failed to determine any relationship with anxiety.

Various studies have reported a relationship between age and depression and/or anxiety. Olveira et al investigated depression and anxiety symptoms and health-related quality of life in 93 bronchiectasis cases. ${ }^{6}$ In this study, age was found to be associated with both depression and anxiety. Likewise, another study reported that the prevalence of anxiety and depression increases but the quality of life decreases with age. ${ }^{9}$ This may result from the fact that the disease becomes chronic and loss of respiratory functions and comorbidities accompany the disease with aging. In the present study, however, we determined no relationship between age and depression and anxiety. This may have resulted from a limited number of cases.

In the recent study, Olveira et al evaluated the relationship between depression/anxiety symptoms and quality of life in bronchiectasis patients. ${ }^{6}$ Olveria et al determined depression symptoms in $20 \%$ and anxiety symptoms in $38 \%$ of bronchiectasis cases and found that the amount of sputum was associated with depression, whereas exacerbation was an association with anxiety. In another study by Olveria et al, the number of exacerbations in the previous year was found to be higher in bronchiectasis cases with anxiety. ${ }^{6}$ In our study, the prevalence of anxiety and depression was as high as in the study by Olveria et al. ${ }^{6}$ However, we questioned the number of emergency room admissions and hospital stays within the last year, but we did not ask history of exacerbations. While hospital stay was not associated with depression or anxiety, emergency room admissions within the year was determined to be an independent risk factor for anxiety and depression. A study investigating the depression-related factors in COPD, chronic airway diseases like bronchiectasis reported that emergency room admissions and hospital stay were more frequent in cases with depression but exacerbations were not significantly high. ${ }^{15}$ In the present study, patients were inquired for emergency room admissions for respiratory problems within the last year, but whether these were exact exacerbations of bronchiectasis was not investigated.

There is strong evidence that a presence of anxiety and depression in cases with chronic respiratory diseases such as bronchiectasis impairs adherence to therapy and reduces patients quality of life. ${ }^{9,16,18}$ In the present study, however, adherence to therapy or quality of life was not assessed, although we inquired the patients about their medication use. Considering particularly the fact that adherence to therapy was associated with the frequency of exacerbations and survival, identification and treatment of anxiety and depression gain more importance. We think that prospective studies are needed on this subject.

Some studies have investigated the relationship between pulmonary function tests $\left(\mathrm{FEV}_{1}, \mathrm{FVC}\right.$, and $\mathrm{FEV}_{1} / \mathrm{FVC}$ ratio) and depression and anxiety. Particularly in $\mathrm{COPD}, \mathrm{FEV}_{1}$ and FVC are considered to be the risk factors for depression., ${ }^{5,15}$ Girón Moreno et al conducted a study in cases with non-cystic fibrosis bronchiectasis and found no significant relationship between $\mathrm{FEV}_{1}$ and depression or anxiety. ${ }^{8}$ Like Girón Moreno et al, ${ }^{8}$ in Olveira et al's study there was no relationship between $\mathrm{FEV}_{1}$ and depression or anxiety in patients with bronchiectasis. ${ }^{9}$

In the study by O'Leary et al, no relationship was found between $\mathrm{FEV}_{1}$ and HADS scores. ${ }^{19}$ Likewise, the present study found no relationship between $\mathrm{FEV}_{1}, \mathrm{FVC}, \mathrm{FEV}_{1} / \mathrm{FVC}$ and depression and anxiety. This may be related to the limited number of cases and/or differences in the extent of disease on HRCT.

Living with a partner has been found as an independent risk factor for both depression and anxiety. Moreover, anxiety symptoms increase with lower education levels. Olveira et al reported a similar result about education level. ${ }^{6}$ It is difficult to explain why living with a partner is associated with depression and anxiety. Evaluation of the partner may give some idea for this association.

Our study has some limitations. Increasing the number of patients enrolled in the study could rise the intensity. Furthermore, patients with high depression and anxiety scores were not referred to psychiatric evaluation.

\section{Conclusion}

In conclusion, patients with non-cystic fibrosis bronchiectasis are at increased risk for anxiety and depression. Admission to an emergency department within the last year and living with a partner were related to depression and anxiety. Also, hemoptysis was correlated with depression, and education level, previous depression history was associated to anxiety. Untreated and undetected depressive and anxiety symptoms may increase physical disability, morbidity, and health care utilization. Future research is needed to address the impact, early detection, and management of anxiety and depression from bronchiectasis. 


\section{Disclosure}

The authors declare no conflicts of interest in this work.

\section{References}

1. Chan ED, Iseman MD. Bronchiectasis. In: Broaddus VC, Mason RJ, Ernst JD, King TE, Lazarus SC, Murray JF, Nadel JA, Slutsky A, Gotway M, editors. Murray \& Nadel's Textbook of Respiratory Medicine, 6th ed. Canada: Saunders Ltd; 2016:853-876.

2. Chalmers JD, Aliberti S, Blasi F. Management of bronchiectasis in adults. Eur Respir J. 2015;45(5):1446-1462.

3. Weycker D, Edelsberg J, Oster G, Tino G. Prevalence and economic burden of bronchiectasis. Clin Pulm Med. 2005;12(4):205-209.

4. Seitz AE, Olivier KN, Adjemian J, Holland SM, Prevots R. Trends in bronchiectasis among medicare beneficiaries in the United States, 2000 to 2007. Chest. 2012;142(2):432-439.

5. Ryu YJ, Chun EM, Lee JH, Chang JH. Prevalence of depression and anxiety in outpatients with chronic airway lung disease. Korean J Intern Med. 2010;25(1):51-57.

6. Olveira C, Olveira G, Gaspar I, et al. Depression and anxiety symptoms in bronchiectasis: associations with health-related quality of life. Qual Life Res. 2013;22(3):597-605.

7. Katon W, Lin EH, Kroenke K. The association of depression and anxiety with medical symptom burden in patients with chronic medical illness. Gen Hosp Psychiatry. 2007;29(2):147-155.

8. Girón Moreno RM, Fernandes Vasconcelos G, Cisneros C, GómezPunter RM, Segrelles Calvo G, Ancochea J. Presence of anxiety and depression in patients with bronchiectasis unrelated to cystic fibrosis. Arch Bronchoneumol. 2013;49(10):415-420.

9. Olveira C, Olveira G, Espildora F, et al. Mediterranean diet is associated on symptoms of depression and anxiety in patients with bronchiectasis. Gen Hosp Psychiatry. 2014;36(3):277-283.
10. Bahali K, Gedik AH, Bilgic A, et al. The relationship between psychological symptoms, lung function and quality of life in children and adolescents with non-cystic fibrosis bronchiectasis. Gen Hosp Psychiatry. 2014;36(5):528-532.

11. Zigmond AS, Snaith RP. The hospital anxiety and depression scale. Acta Psychiatry Scand. 1983;67(6):361-370.

12. Aydemir Ö, Güvenir T, Küey S, Kültür S. Turkish version validation of hospital anxiety and depression scale. Turkish J Psychiatr. 1997;8: 280-287. Turkish.

13. Marcus M, Yasamy MT, Ommeren Mv, Chisholm D, Saxena S. Depression: a global public health concern. WHO department of mental health and substance abuse. Available from: www.who.int/mental_health/ management/depression. Accessed October 8, 2016.

14. Wagena EJ, Arrindell WA, Wouters EF, van Schayck CP. Are patients with COPD psychologically distressed? Eur Respir J. 2005;26(2): 242-248.

15. Martinez Rivera C, Costan Galicia J, Alcázar Navarrete B, et al. Factor associated with depression in COPD: a multicenter study. Lung. 2016;194(3):335-343.

16. Di Marco F, Verga M, Reggente M, et al. Anxiety and depression in COPD patients: the roles of gender and disease severity. Respir Med. 2006;100(10):1767-1774.

17. Goldbeck L, Besier T, Hinz A, Singer S, Quittner AL, TIDES Group. Prevalence of symptoms of anxiety and depression in German patients with cystic fibrosis. Chest. 2010;138(4):929-936.

18. DiMatteo MR, Giordani PJ, Lepper HS, Croghan TW. Patient adherence and medical treatment outcomes: a meta-analysis. Med Care. 2002; 40(9):794-811.

19. O'Leary CJ, Wilson CB, Hansell DM, Cole PJ, Wilson R, Jones PW. Relationship between psychological well-being and lung health status in patients with bronchiectasis. Respir Med. 2002;96(9):686-692.
Neuropsychiatric Disease and Treatment

\section{Publish your work in this journal}

Neuropsychiatric Disease and Treatment is an international, peerreviewed journal of clinical therapeutics and pharmacology focusing on concise rapid reporting of clinical or pre-clinical studies on a range of neuropsychiatric and neurological disorders. This journal is indexed on PubMed Central, the 'PsycINFO' database and CAS,

\section{Dovepress}

and is the official journal of The International Neuropsychiatric Association (INA). The manuscript management system is completely online and includes a very quick and fair peer-review system, which is all easy to use. Visit http://www.dovepress.com/testimonials.php to read real quotes from published authors. 